\title{
Effect of temperature and mating pair on tribological properties of DLC and GLC coatings under high pressure lubricated by MoDTC and ZDDP
}

\author{
Kang LIU ${ }^{1}$, Jia-jie KANG ${ }^{1,2,3, *}$, Guang-an ZHANG ${ }^{4, *}$, Zhi-bin $\mathbf{L U}^{4}$, Wen YUE $\mathbf{E}^{1,2,3}$ \\ ${ }^{I}$ School of Engineering and Technology, China University of Geosciences (Beijing), Beijing 100083, China \\ ${ }^{2}$ Key Laboratory of Deep GeoDrilling Technology of Ministry of Natural Resources, Beijing 100083, China \\ ${ }^{3}$ Zhengzhou Institute, China University of Geosciences (Beijing), Zhengzhou 451283, China \\ ${ }^{4}$ State Key Laboratory of Solid Lubrication, Lanzhou Institute of Chemical Physics, Chinese Academy of Sciences, Lanzhou \\ 730000, China
}

Received: 02 March 2020 / Revised: 05 May 2020 / Accepted: 14 June 2020

(C) The author(s) 2020 .

\begin{abstract}
Diamond-like carbon (DLC) and graphite-like carbon (GLC) coatings have good prospects for improving the surface properties of engine parts. However, further understanding is needed on the effect of working conditions on tribological behaviors. In this study, GLC and two types of DLC coatings were deposited on GCr15 substrate for investigation. The friction and wear properties of self-mated and steel-mated pairs were evaluated. Two temperatures $\left(25\right.$ and $90{ }^{\circ} \mathrm{C}$ ), three lubrication conditions (base oil, molybdenum dithiocarbamate (MoDTC)-containing oil, MoDTC+zinc dialkyldithiophosphate (ZDDP)containing oil), and high Hertz contact stress (2.41 GPa) were applied in the experiments. The results showed that high temperature promoted the effect of ZDDP on steel-mated pairs, but increased wear under base oil lubrication. The increased wear for steel-mated pairs lubricated by MoDTC-containing oil was due to abrasive wear probably caused by $\mathrm{MoO}_{3}$ and $\beta-\mathrm{FeMoO}_{4}$. It was also found that in most cases, the tribological properties of self-mated pairs were better than those of steel-mated pairs.
\end{abstract}

Keywords: diamond-like carbon (DLC); graphite-like carbon (GLC); mating pair; temperature; oil additives

\section{Introduction}

In recent years, the increased number of motor vehicles has made automobile exhaust emissions an issue of concern in the society. Excessive emissions not only cause severe air pollution but also energy waste and economic losses. To achieve the goal of energy conservation and emission reduction, the European Union has published emission standards, such as "Euro V" and "Euro VI" [1]. For passenger cars, approximately $28.8 \%$ of the energy generated by fuel is used to deal with unnecessary friction in components, such as the engine, whereas the energy required to drive the car accounts for only $21.5 \%$ [2]. Thus, reducing the friction of transmission parts is a major challenge for improving fuel efficiency and reducing emission.

Diamond-like carbon (DLC) coating possesses excellent friction reduction and wear resistance characteristics as well as good chemical inertness $[3,4]$. Graphite-like carbon (GLC) coating is mainly comprised of highly disordered $\mathrm{sp}^{2}$ bonds with small graphite clusters [5] that exhibit good tribological properties and high load capacity under various conditions [6-10]. Both DLC and GLC are excellent candidates for improving the tribological properties

* Corresponding authors: Jia-jie KANG, E-mail: kangjiajie@cugb.edu.cn; Guang-an ZHANG, E-mail: gazhang@licp.cas.cn 
of engine components.

The two most commonly used lubricant additives, molybdenum dithiocarbamate (MoDTC) and zinc dialkyldithiophosphate (ZDDP), were designed for traditional ferrous material, and act on the surface of the mating pair that causes the tribochemical reaction to improve friction and wear behavior [11, 12]. Numerous studies have been conducted on the synergistic effect of MoDTC and ZDDP with DLC films. $\mathrm{MoS}_{2}$ is one of the decomposition products of MoDTC that exhibits low shear strength and lamellar structure. Previous studies have shown that its friction-reducing capability is closely related to the amount of $\mathrm{MoS}_{2}$ [13-15]. MoDTC has been found to cause significant wear on some DLC coatings when sliding against steel. The wear acceleration could be attributed to the formation of abrasive $\mathrm{MoO}_{3}[16,17]$ or $\mathrm{MoC}_{x}[18]$ particles, the chemical reaction between Mo compound and $C$ dangling bond [19], or the oxidation of carbon films [20]. $\beta-\mathrm{FeMoO}_{4}$ was also found to be a tribochemical product of MoDTC [21], which may contribute to the increased wear of DLC. Although different wear mechanisms have been proposed, it is clear that the ferrous surface-induced the severe wear caused by MoDTC. ZDDP eliminates such wear in most cases. When blended with MoDTC, ZDDP can provide abundant $S$ elements to promote the formation of decomposition products, $\mathrm{MoS}_{x}$ [22]. Previous studies suggest that in the case of DLC/ steel, ZDDP prevents the dangling bonds on the carbon surface from forming covalent bonds with the ferrous surface by creating a reaction film, thereby eliminating chemical wear. The reaction film also reduces mechanical wear to a certain extent [23]. ZDDP is believed to inhibit the graphitization of DLC films during friction, thus reducing surface wear [24]; graphitization hinders the generation of ZDDP-derived tribofilms [25]. For DLC/DLC and DLC/steel, previous studies showed that tribofilm derived from ZDDP formed on the carbon film, but the morphology was far from the pad-like anti-wear film generated on the steel/steel tribopair [26]. Through in situ tribological tests, the mixed layer of zinc sulfide and metal oxides that formed on steel were not found on hydrogenated DLC, which could be the reason for the discontinuity and low durability of the tribofilm [27]. However, most of the studies mentioned above were carried out at the Hertz contact stress of $1 \mathrm{GPa}$ and a temperature of approximately $100{ }^{\circ} \mathrm{C}$. Engine components, such as the valve cam, can sustain higher contact pressure, and engine wear frequently occurs during the cold start owing to the lack of lubricating oil available to the engine components when the engine is still at room temperature. To fully investigate the tribological characteristics of DLC under actual engine operating conditions, it is important to conduct tribological experiments under normal temperature and high Hertz contact stress. Few studies have been conducted on the tribological behaviors of oil-lubricated GLC. Thus, the effect of lubricating oil additives on GLC films requires further research.

In this study, the experiments were conducted on the GLC coating and two types of DLC coatings, hydrogenated amorphous carbon $(\mathrm{a}-\mathrm{C}: \mathrm{H})$ and tetrahedral amorphous carbon (ta-C) coatings. The tribological behaviors of self-mated tribopairs and those sliding against GCr15 steel were investigated under high Hertz contact stress (2.41 GPa), lubricated by base oil and oils containing MoDTC and MoDTC + ZDDP. Their mechanisms were also discussed. The main purpose of the experiment is to investigate the effects of temperature and mating pairs on tribochemical reactions between carbon-based coatings and oil additives, and determine the mechanisms of the friction and wear behaviors of the coatings under high Hertz contact stress.

\section{Experimental}

\subsection{Deposition of the films}

Before deposition, the GCr15 steel substrates (dimensions of $\phi 20 \mathrm{~mm} \times 10 \mathrm{~mm}$ ) were each ultrasonically cleaned in petroleum ether, acetone, and alcohol for $20 \mathrm{~min}$, and then dried with nitrogen. The a$\mathrm{C}: \mathrm{H}$ and GLC coatings were deposited on the GCr15 substrates with chromium transitional layers using the unbalanced magnetron sputtering ion deposition system (UDP650-4, Teer, England). The ta-C coating was deposited on the substrate through multi-arc ion plating (Flexicoat 850, Hauzer, the Netherlands). A graphite target was used to provide the carbon in all deposition processes. The deposition details of the three coatings are listed in Table 1. 
Table 1 Deposition details of the coatings.

\begin{tabular}{cccccccc}
\hline Coatings & Precursors & $\begin{array}{c}\text { Gas flow } \\
(\mathrm{sccm})\end{array}$ & Interlayer & $\begin{array}{c}\text { Target voltage } \\
(\mathrm{V})\end{array}$ & $\begin{array}{c}\text { Target current } \\
(\mathrm{A})\end{array}$ & $\begin{array}{c}\text { Bias voltage } \\
(\mathrm{V})\end{array}$ & $\begin{array}{c}\text { Deposition } \\
\text { time }(\mathrm{h})\end{array}$ \\
\hline $\mathrm{GLC}$ & $\mathrm{Ar}$ & 16 & $\mathrm{Cr}$ & 750 & 3.5 & 70 & 4 \\
$\mathrm{a}-\mathrm{C}: \mathrm{H}$ & $\mathrm{Ar}+\mathrm{C}_{4} \mathrm{H}_{10}$ & $16+4$ & $\mathrm{Cr}$ & 640 & 3.5 & 70 & 4 \\
ta-C & $\mathrm{Ar}$ & 90 & $\mathrm{Cr}$ & - & 60 & 50 & 0.625 \\
\hline
\end{tabular}

\subsection{Base oil and additives}

An API-III base oil with viscosities of $6.383 \mathrm{~mm}^{2} / \mathrm{s}$ and $18.851 \mathrm{~mm}^{2} / \mathrm{s}$ at 80 and $40{ }^{\circ} \mathrm{C}$, respectively, was selected. The elemental compositions of 2ethylhexyl MoDTC are Mo 10 at\% and S 11 at $\%$. The compositions of ZDDP are 10 at $\%$ Zn, 8 at\% P, and 15 at $\%$ S. Both additives were used separately with a mass ratio of $1 \%$.

\subsection{Tribological tests}

The experiments were conducted on an UMT-3 Bruker Tribolab reciprocating friction and wear tester. The fixed coated or uncoated GCr15 ball, with a diameter of $6 \mathrm{~mm}$, was in the upper position, whereas the reciprocating coated substrate was in the lower position. The load applied in this experiment was $50 \mathrm{~N}$, which provided a maximum initial contact pressure of $2.41 \mathrm{GPa}$. Each test lasted for $1 \mathrm{~h}$ at 25 or $90{ }^{\circ} \mathrm{C}$. The reciprocating amplitude was $5 \mathrm{~mm}$ and the frequency was $5 \mathrm{~Hz}$. The wear track of the coated substrate was measured on the K-tencor D-100 two-dimensional profiler, and the wear scar of the balls was observed using a scanning electron microscopy (SEM). The two-dimensional profiler was automatically integrated to calculate the area of the wear track at the cross-section after the flattened baseline was processed. Three crosssectional areas were sampled (two from both ends and the other from the middle of the wear track), averaged, and then multiplied by the reciprocating amplitude $(5 \mathrm{~mm})$ to calculate the wear volume. The wear rate $(K)$ of the DLC coatings was based on the wear volume of the coated disc substrate mentioned above, which was calculated by the following equation:

$$
K=\frac{\Delta V}{F \times S}
$$

where $\Delta V\left(\mathrm{~mm}^{3}\right)$ is the wear volume, $F(\mathrm{~N})$ is the applied normal load, and $S(\mathrm{~m})$ is the sliding distance.

Each experiment was conducted three times to ensure repeatability, and the average values were adopted in the study.

\subsection{Surface analysis}

Field-emission SEM (FESEM, HitachiS4800) was used to obtain the cross-section image of the coatings. The TTX-NHT2 nano-indenter (Anton Paar, Austria) was employed to investigate the hardness and elastic modulus of the DLC coating; the test depth was approximately $10 \%$ of the coating thickness. After the experiment, the morphologies of wear tracks and wear scars, and elements in the wear tracks were studied through SEM (TESCAN MIRA3) and energy-dispersive spectroscopy (EDS, Bruker XFlash 630). Further investigation of the transfer layer and degree of graphitization on the wear scars and wear tracks were performed by Raman spectroscopy (532 $\mathrm{nm} \mathrm{Ar}^{+}$laser excitation source, LabRam HR 800).

\section{Results}

\subsection{Properties of the coatings}

The cross-sectional surface morphologies of GLC, a-C:H, and ta-C coatings are shown in Fig. 1(a). It was observed that the thickness of GLC and a-C:H coatings was $1.8 \mu \mathrm{m}$. Owing to the high internal stress of the ta-C coating, the thickness was controlled at $0.66 \mu \mathrm{m}$ to ensure the high adhesion strength. The thickness of $\mathrm{Cr}$ interlayers ranged from 0.2 to $0.3 \mu \mathrm{m}$ for the three coatings. The deposited grains of the GLC coating was uniform, exhibiting a graphitic structure. The a-C:H coating exhibited a dense columnar structure without obvious gaps. 
(a)

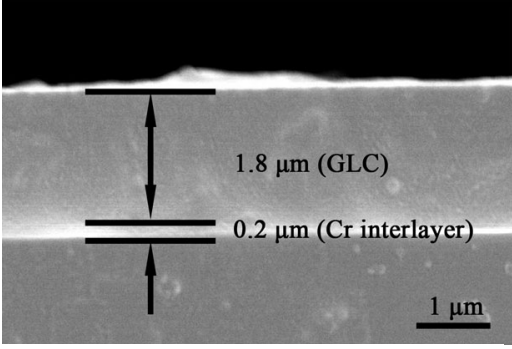

GLC

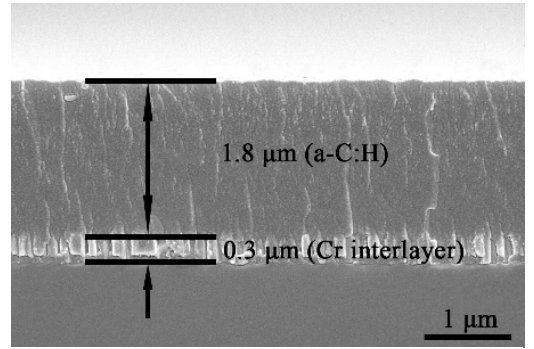

$\mathrm{a}-\mathrm{C}: \mathrm{H}$

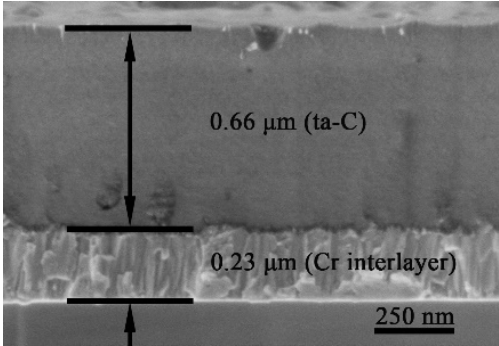

ta-C

(b)
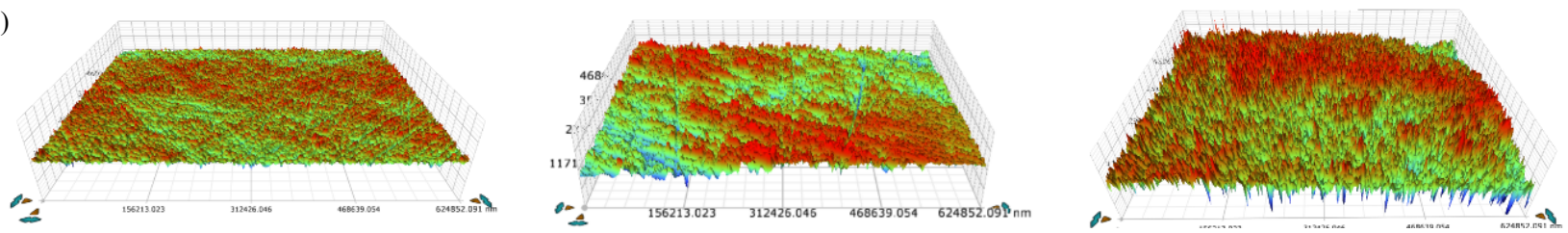

Fig. 1 (a) Cross-sectional SEM images and (b) 3D surface morphological images of the coatings.

For the ta-C coating, the grain size was relatively small and the structure was dense. As seen from the 3D surface morphologicaies in Fig. 1(b), the GLC and a-C:H coatings showed smooth surfaces with only a few bulges. The surface of the ta-C coating seemed quite rough, exhibiting lots of sharp particles and defects.

The mechanical properties of the coatings and GCr15 ball are listed in Table 2. Among the three coatings, ta- $\mathrm{C}$ had the highest hardness and elastic modulus of 64.0 and $442.0 \mathrm{GPa}$, respectively, which were attributed to the greater number of $\mathrm{sp}^{3}$ hybrid bonds in ta-C compared with the other coatings. The roughness of ta- $\mathrm{C}$ was much higher compared with the other two coatings, corresponding to its surface morphology. This phenomenon was explained by the large number of carbon ions that accumulated on the $\mathrm{Cr}$ interlayer and formed large particles, which increased the surface roughness.

\subsection{Lubrication regime}

The $\lambda$ is the ratio of elastohydrodynamic (EHD)

Table 2 Mechanical properties of the coatings and GCr15 ball.

\begin{tabular}{lcccc}
\hline Specimen & $\begin{array}{c}\text { Hardness } \\
(\mathrm{GPa})\end{array}$ & $\begin{array}{c}\text { Elastic } \\
\text { modulus } \\
(\mathrm{GPa})\end{array}$ & $\begin{array}{c}\text { Adhesion } \\
\text { strength } \\
(\mathrm{N})\end{array}$ & $\begin{array}{c}\text { Roughness } \\
(\mathrm{nm})\end{array}$ \\
\hline GLC & 14.2 & 163.0 & 19.3 & 11.0 \\
$\mathrm{a}-\mathrm{C}: \mathrm{H}$ & 25.0 & 218.0 & 15.4 & 12.0 \\
ta-C & 64.0 & 442.0 & 18.5 & 40.7 \\
GCr15 & 7.3 & 208.0 & - & 25.0 \\
\hline
\end{tabular}

film thickness and composite surface roughness, which was used to determine the lubrication regime in this experiment. The minimum EHD film thickness $\left(h_{\min }\right)$ was calculated by the Hamrock-Dowson formula [28]:

$$
h_{\min }=3.63\left(\frac{\eta V}{E^{\prime} R}\right)^{0.68}\left(\alpha E^{\prime}\right)^{0.49}\left(\frac{F}{E^{\prime} R^{2}}\right)^{-0.073}\left(1-\mathrm{e}^{-0.68 k}\right) R
$$

where $\eta$ is the fluid viscosity, $V$ is the sliding velocity, $E^{\prime}$ is the effective elastic modulus, $\alpha$ is the viscosity-pressure coefficient, $R$ is the radius of the mating ball, $F$ is the applied normal load, and $k$ is the ellipticity.

The $\lambda$ is calculated by the following Eq. (3) [29]:

$$
\lambda=\frac{h_{\min }}{\sigma}=\frac{h_{\min }}{\sqrt{\sigma_{1}^{2}+\sigma_{2}^{2}}}
$$

where $\sigma$ is the combined surface roughness of the coating $\left(\sigma_{1}\right)$ and mating ball $\left(\sigma_{2}\right)$.

According to the relevant parameters, the minimum film thickness was approximately $6.97-7.84 \mathrm{~nm}$ at $25{ }^{\circ} \mathrm{C}$, which decreased to $2.33-2.62 \mathrm{~nm}$ at $90{ }^{\circ} \mathrm{C}$. The combined surface roughness of all tribopairs was in the range of $11.0-40.7 \mathrm{~nm}$. Therefore, the $\lambda$ ranged from 0.17 to 0.71 at $25{ }^{\circ} \mathrm{C}$, and 0.06 to 0.24 at $90{ }^{\circ} \mathrm{C}$, revealing that the lubrication regime in the experiment was boundary lubrication.

\subsection{Tribological behaviors}

\subsubsection{Friction coefficient (COF)}

Figures 2 and 3 show the COF curves at 25 and 
$90{ }^{\circ} \mathrm{C}$. At $25{ }^{\circ} \mathrm{C}$, the $\mathrm{COF}$ of all tribopairs fluctuated greatly. Under base oil lubrication, the lowest COF was achieved by ta-C/steel at approximately 0.07 . The COF of GLC/steel was approximately 0.11 , which is significantly higher than that of GLC/
GLC at 0.08. The friction-reducing effect of MoDTC on DLC/steel and GLC/steel was more obvious, but also caused a larger range of COFs than in the base oil. For GLC, the COF ranged from 0.06 to 0.20. Under MoDTC lubrication, the average COF of
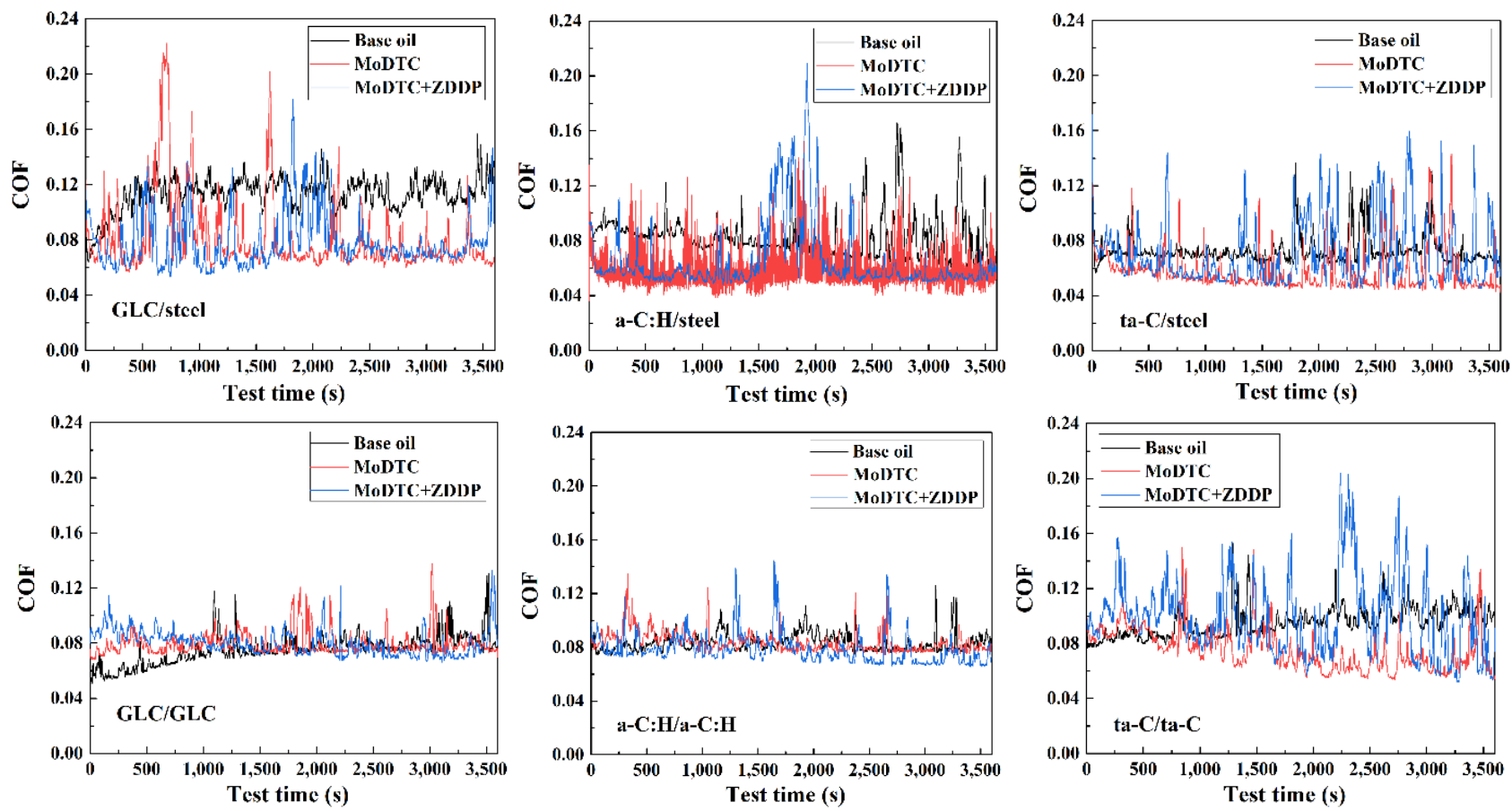

Fig. 2 COF curves vs. time of different tribopairs at $25{ }^{\circ} \mathrm{C}$.
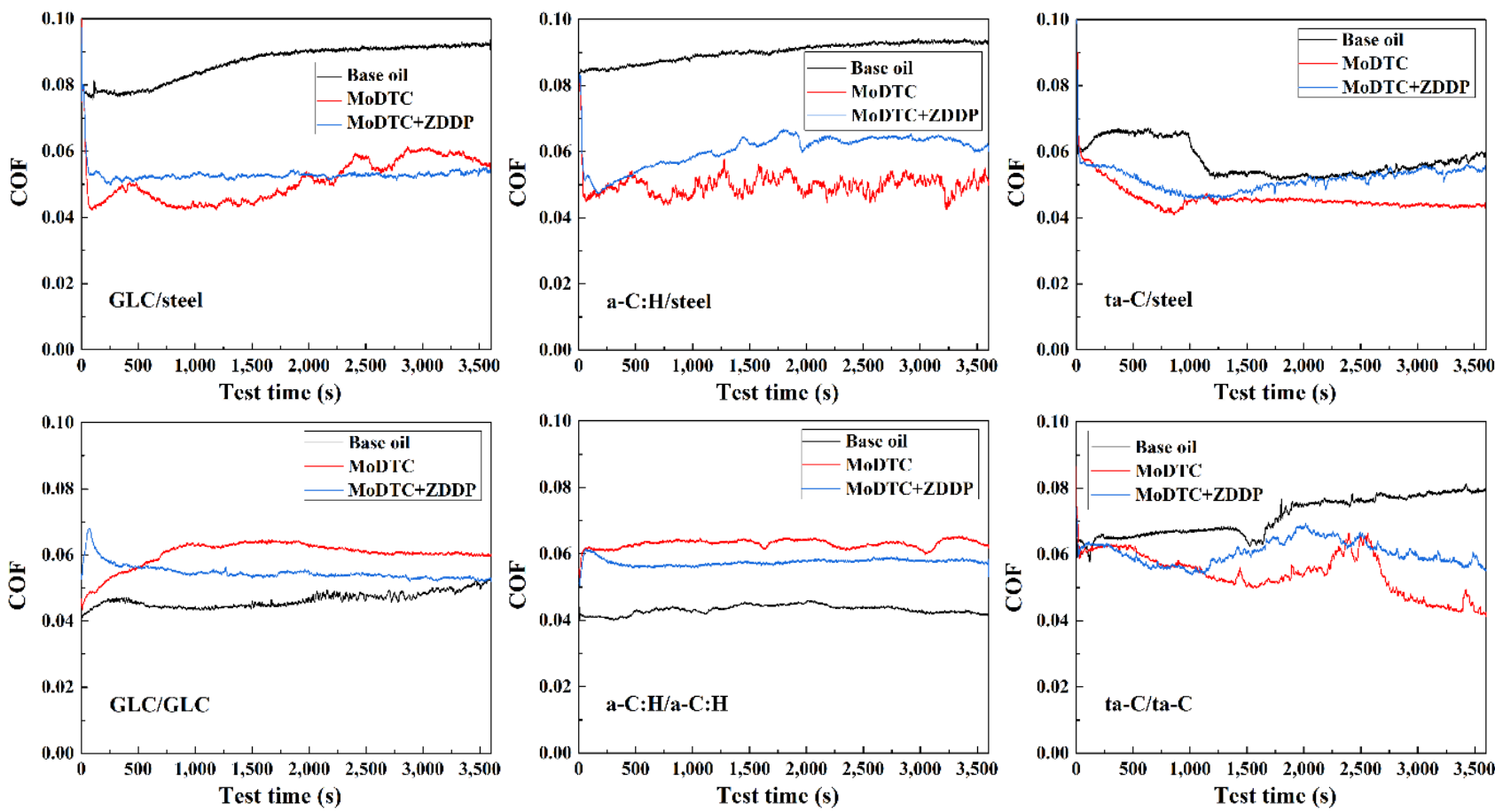

Fig. 3 COF curves vs time of different tribopairs at $90{ }^{\circ} \mathrm{C}$. 
GLC/steel and a-C:H/steel was approximately 0.06 . The lower value of ta-C/steel reached approximately 0.05 and showed a downward trend during the friction process. ZDDP had a minor effect on the friction-reduction and did not reduce the fluctuation of the COF. For the self-mated tribopairs, the effect of additives on the COF was not obvious. However, ta-C/ta-C is a special case. The wear rate (to be discussed in the next section) confirmed that ta$\mathrm{C} /$ ta-C was worn out under all three lubrication conditions. Hence, the COFs were not significant for the investigation. Compared with the steel-mated tribopairs, the COFs of the self-mated tribopairs were more stable.

At $90{ }^{\circ} \mathrm{C}$, the $\mathrm{COF}$ of each tribopair was very stable. First, it should be mentioned that ta-C/ta-C was worn out under all three lubrication conditions, the same as at $25{ }^{\circ} \mathrm{C}$. The ta-C coating was also worn out when wearing against the steel ball under base oil lubrication, as indicated by the sudden decrease of the COF. Under base oil lubrication, the COFs of all tribopairs were lower and more stable than those at $25{ }^{\circ} \mathrm{C}$. The COF of a-C:H/a$\mathrm{C}: \mathrm{H}$ was the lowest at approximately 0.04 , which is half of that at $25{ }^{\circ} \mathrm{C}$. MoDTC reduced the COF of steel-mated tribopairs to half of that in the base oil but significantly increased that of self-mated tribopairs. For the steel-mated tribopairs, the COF increased slightly when ZDDP was contained in the oil, compared to MoDTC-containing oil., but the effect was opposite for the self-mated tribopairs. Nonetheless, the overall effect was not significant.

\subsubsection{Wear rate}

Figure 4 shows the wear rates of coatings for the steel-mated and self-mated tribopairs at $25{ }^{\circ} \mathrm{C}$. For the steel-mated tribopairs, the wear rate of ta- $\mathrm{C} /$ steel was the highest under base oil lubrication, which was six times of that of a-C:H/steel. The effect of MoDTC on aggravating the wear of DLC/ steel, as reported in Refs. [16, 26, 30], was also observed in this experiment. However, it is worth noting that MoDTC had anti-wear effects on ta-C/ steel instead. On the other hand, ZDDP had a limited effect on reducing wear for DLC/steel and GLC/steel. For the self-mated tribopairs, the wear rates of GLC/GLC and a-C:H/a-C:H were very low, but that of ta-C/ta-C was extremely high such that it became worn out. The effect of additives on the wear rate was small. The only exception was ZDDP, which increased the wear of GLC self-mated pairs.

Figure 5 shows the wear rates of coatings for the steel-mated and self-mated tribopairs at $90{ }^{\circ} \mathrm{C}$. It can be seen that the wear rates of the steel-mated tribopairs under base oil lubrication almost doubled, which wore out ta-C/steel. MoDTC aggravated the wear of GLC/steel but had little influence on the wear rate of a-C:H/steel. For ta-C/steel, it effectively improved the wear resistance of the coating. The anti-wear effect of ZDDP on the steel-mated tribopairs greatly improved, reducing the wear rate to a very low level. The wear rate of self-mated tribopairs under base oil lubrication increased, but it was still much less than that of the steel-mated tribopairs. MoDTC exacerbated the wear of GLC/GLC, but ZDDP suppressed this phenomenon. For a-C:H/a$\mathrm{C}: \mathrm{H}$, the additives played anti-wear roles. However, ta-C/ta-C suffered the same severe wear as that at $25{ }^{\circ} \mathrm{C}$.
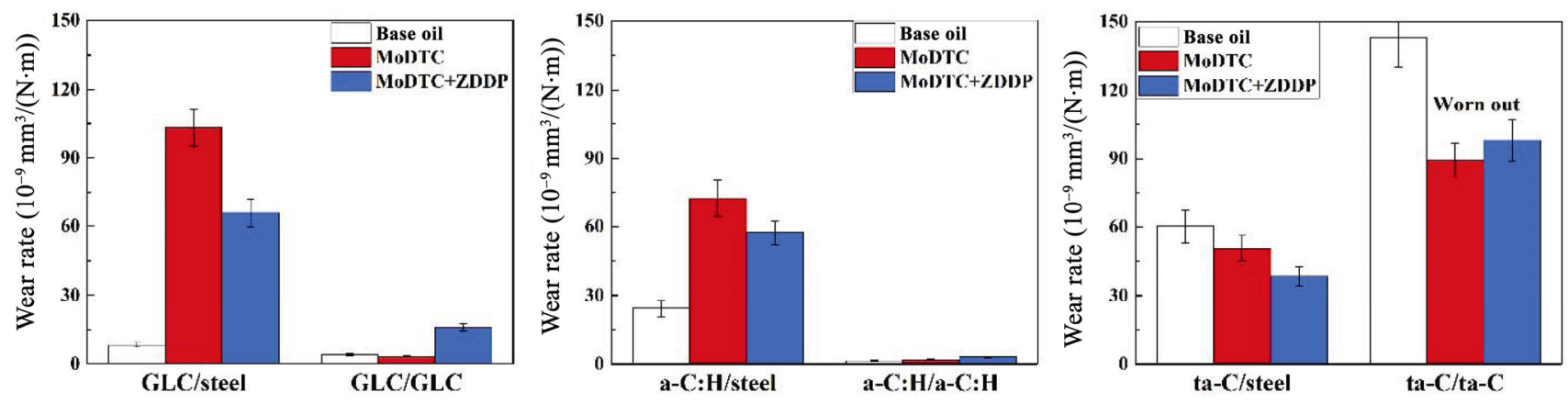

Fig. 4 Wear rates of different tribopairs at $25{ }^{\circ} \mathrm{C}$. 

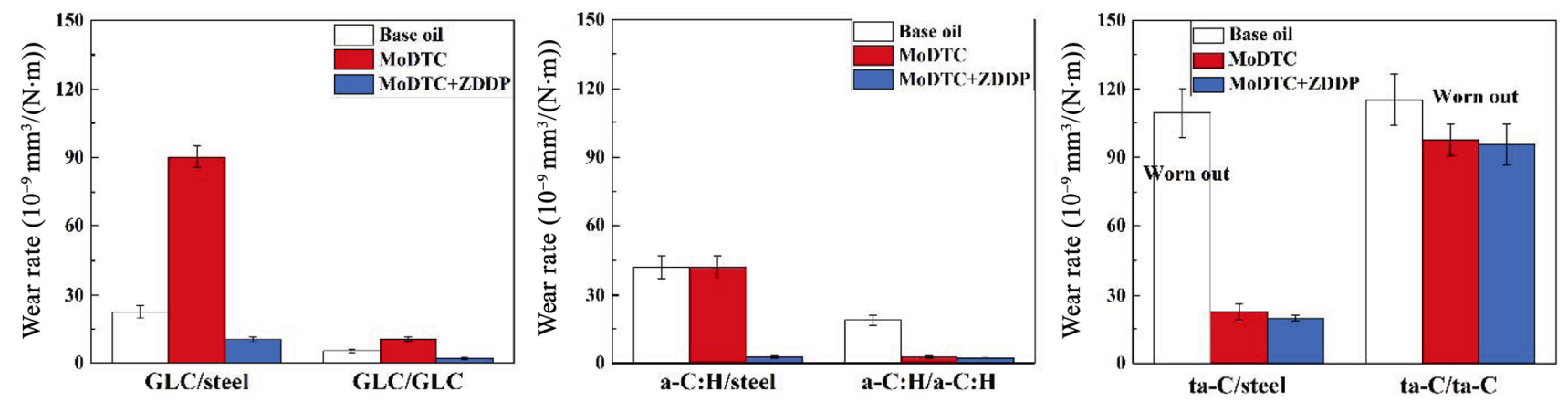

Fig. 5 Wear rates of different tribopairs at $90{ }^{\circ} \mathrm{C}$.

\subsection{SEM and EDS analysis}

The wear tracks of the coated substrate were observed using SEM and the morphological images under MoDTC+ZDDP lubrication and base oil lubrication conditions were given in Figs. 6 and 7, respectively. Figures 4 and 5 show that the temperature had obvious effects on the wear rates of a-C:H/a-C:H lubricated by base oil, and that of the steel-mated pair lubricated by MoDTC+ZDDP-containing oil. Therefore, the wear tracks of GLC/steel and a-C:H/ steel lubricated by MoDTC+ZDDP-containing oil, and ta-C/steel and a-C:H/a-C:H lubricated by base oil, were compared.

Under the lubrication of MoDTC+ZDDP-containing oil, it was observed that the width of the wear track on GLC at $90{ }^{\circ} \mathrm{C}$, the number of furrows, and the depth of the wear track significantly decreased, as shown in Fig. 6. For a-C:H/steel, no spalling of the coatings appeared at higher temperatures, and the width of the wear track was also reduced.

Under base oil lubrication, high temperature aggravated wear (Fig. 7). For ta-C/steel, the width of the wear track increased, and the worn-out area of the coating also increased significantly. For $\mathrm{a}-\mathrm{C}: \mathrm{H} / \mathrm{a}-\mathrm{C}: \mathrm{H}$, the number of furrows increased and was distributed continuously on the wear track.

Since the tribofilms were mostly generated on the mating ball, it is necessary to observe the morphologies of the wear scar on the balls, and then use EDS to analyze the element content of the tribofilm that formed on the coating. Figure 8 and Table 3 show that for GLC/GLC lubricated by MoDTC-containing oil, a relatively dense friction reaction film, rich in Mo, S, O, and other elements, was formed on the wear scar. However, the analysis
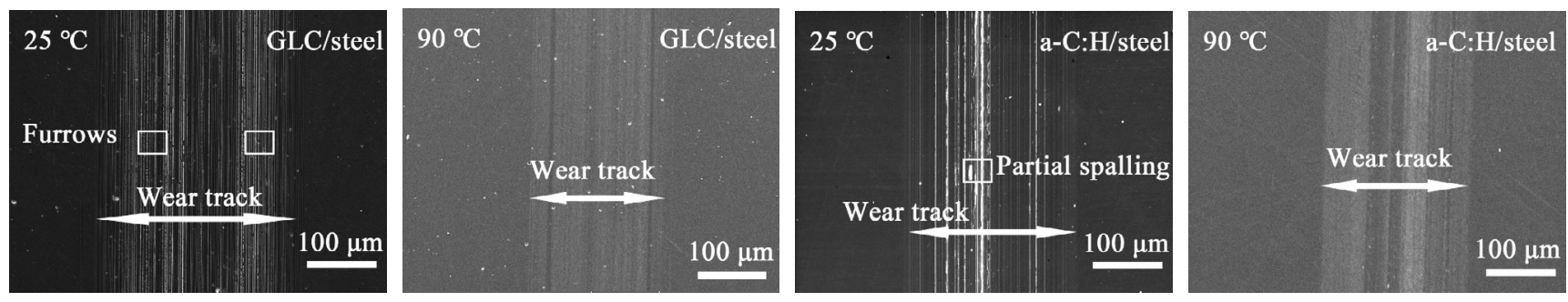

Fig. 6 SEM images of the wear tracks under MoDTC+ZDDP lubrication.
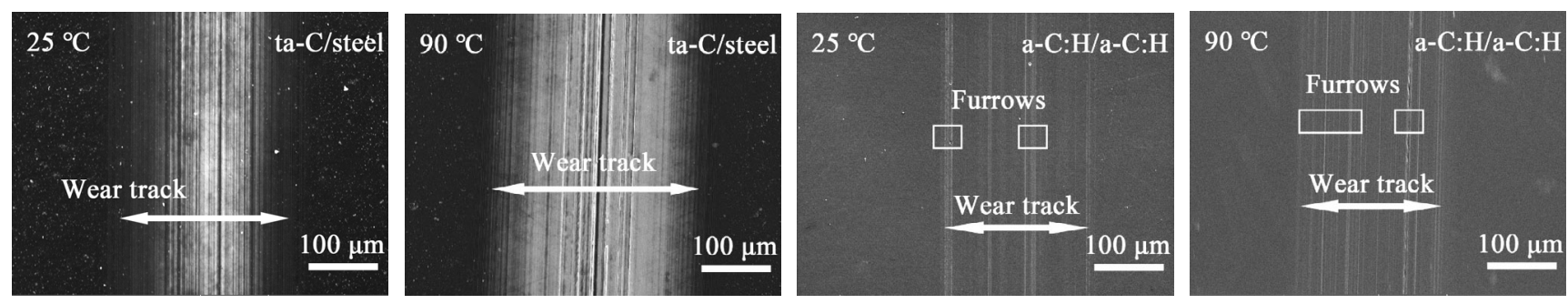

Fig. 7 SEM images of the wear tracks under base oil lubrication. 


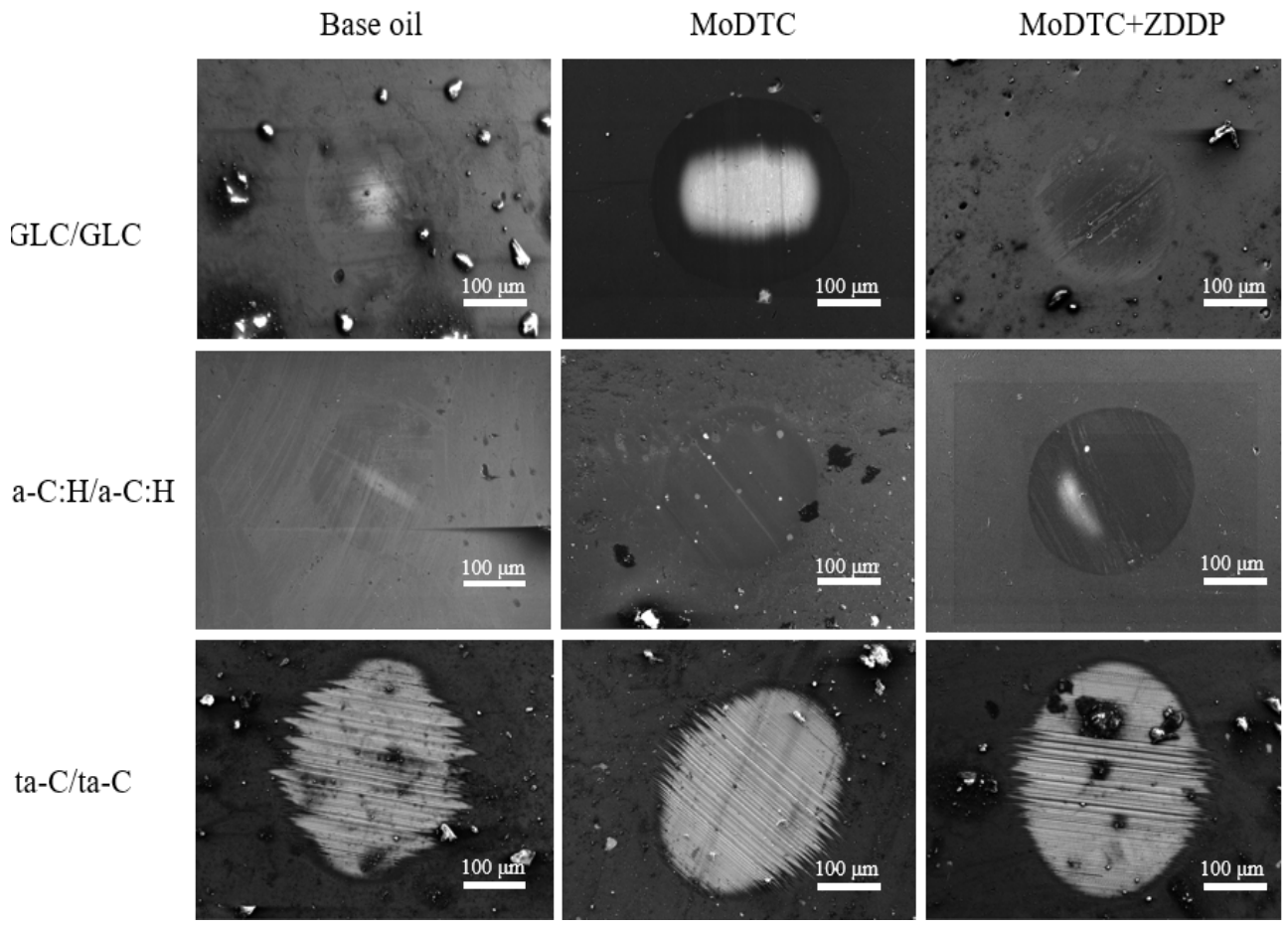

Fig. 8 SEM images of wear scars on the self-mated balls at $90{ }^{\circ} \mathrm{C}$.

Table 3 Element content of the wear scars on the self-mated balls at $90{ }^{\circ} \mathrm{C}$.

\begin{tabular}{|c|c|c|c|c|c|c|c|}
\hline \multirow{2}{*}{ Mating pairs and lubricated conditions } & \multicolumn{7}{|c|}{ Element content (at \%) } \\
\hline & $\mathrm{C}$ & $\mathrm{O}$ & $\mathrm{Fe}$ & Mo & $\mathrm{S}$ & $\mathrm{Zn}$ & $\mathrm{P}$ \\
\hline GLC/GLC, base oil & 97.37 & 2.29 & 0.30 & - & - & - & - \\
\hline GLC/GLC, MoDTC & 76.83 & 10.01 & 3.43 & 4.89 & 4.59 & - & - \\
\hline GLC/GLC, MoDTC+ZDDP & 96.65 & 3.02 & 0.17 & 0.02 & 0.08 & 0.03 & 0.03 \\
\hline a-C:H/a-C:H, base oil & 98.32 & 1.39 & 0.28 & - & - & - & - \\
\hline $\mathrm{a}-\mathrm{C}: \mathrm{H} / \mathrm{a}-\mathrm{C}: \mathrm{H}, \mathrm{MoDTC}$ & 94.42 & 1.44 & 0.39 & 2.39 & 3.64 & - & - \\
\hline $\mathrm{a}-\mathrm{C}: \mathrm{H} / \mathrm{a}-\mathrm{C}: \mathrm{H}, \mathrm{MoDTC}+\mathrm{ZDDP}$ & 98.05 & 1.44 & 0.39 & - & 0.08 & - & - \\
\hline ta-C/ta-C, base oil & 49.13 & 11.86 & 38.91 & - & - & - & - \\
\hline ta-C/ta-C, MoDTC & 30.72 & 5.52 & 57.28 & 1.52 & 2.18 & - & - \\
\hline ta-C/ta-C, MoDTC+ZDDP & 55.16 & 3.45 & 38.81 & 0.71 & 1.33 & 0.39 & 0.15 \\
\hline
\end{tabular}

of the results of tribological experiments indicates that this tribofilm did not improve tribological performance. Instead, it exacerbated the wear on the coated substrate. Under the lubrication of MoDTC+ZDDP-containing oil, a discontinuous pale film appeared on the surface of the mating ball, which was similar to the friction reaction film described in other literatures. EDS analysis found that few $\mathrm{P}$ and $\mathrm{Zn}$ elements appeared. Compared with GLC/GLC, the oxygen content of the wear scar of a-C:H/a-C:H was relatively low, and the Mo and $S$ content decreased after the addition of
ZDDP; there was also no enrichment of $\mathrm{Zn}$ or P. For ta-C/ta-C, the coating was worn out under all lubrication conditions. Some glassy pad-like reaction films containing $\mathrm{P}, \mathrm{Zn}, \mathrm{S}, \mathrm{Fe}$, and Mo appeared on the exposed steel substrate lubricated by MoDTC + ZDDP-containing oil, which is consistent with the morphology of the tribofilm that formed on the ferrous surface.

The morphologies and element content of wear scars on steel-mated balls at $90{ }^{\circ} \mathrm{C}$ are shown in Fig. 9 and Table 4, respectively. For GLC/steel, the transferred carbon is seen at the center of the wear 
scar under base oil lubrication. The wear scar became larger when lubricated by MoDTC-containing oil, and the deep furrows on it indicate that the wear mechanism was abrasive wear. The addition of ZDDP helped recover the worn surfaces; it formed a continuous tribofilm containing $\mathrm{C}, \mathrm{O}, \mathrm{Fe}$, and a small amount of Mo, S, Zn, and P. The wear condition of a-C:H/steel was similar to the above phenomenon. It is worth noting that the addition of MoDTC caused a large amount $(71.25 \%)$ of the transferred carbon. For ta-C/steel, the wear scar became much larger compared with that on the other two tribopairs.

\subsection{Raman analysis}

Raman spectroscopy is widely used to distinguish the bonding states of the carbon phase in GLC and DLC coatings. The Raman spectrum of the GLC and DLC coatings generally shows a broad peak at approximately $1,500 \mathrm{~cm}^{-1}$, which can be decomposed into two peaks corresponding to the $\mathrm{D}$ peak and $\mathrm{G}$ peak, respectively. The D peak shoulder is located at approximately $1,360 \mathrm{~cm}^{-1}$, and the $G$ peak is

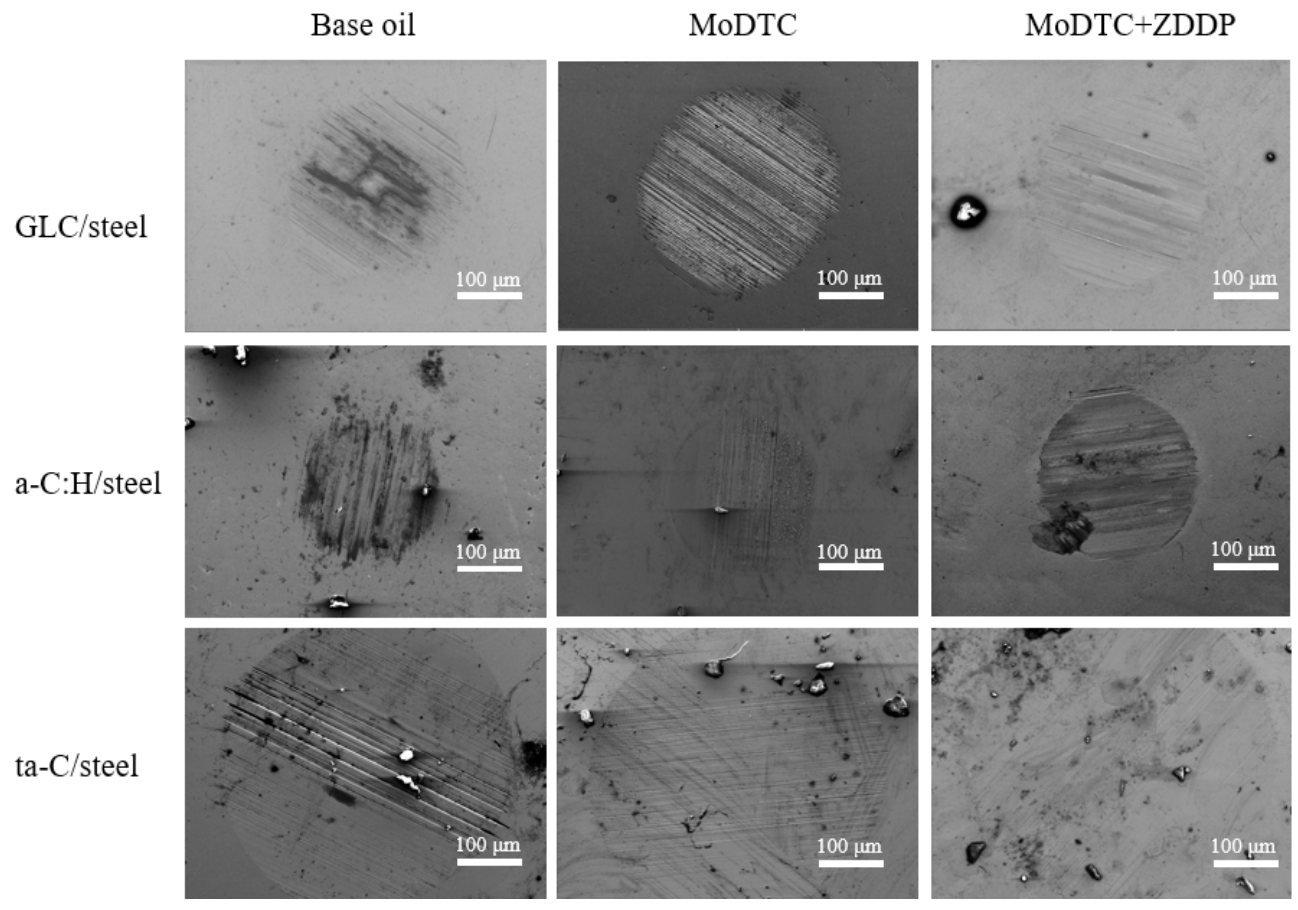

Fig. 9 SEM images of wear scars on the steel-mated balls at $90{ }^{\circ} \mathrm{C}$.

Table 4 Element content of the wear scars on the steel-mated balls at $90{ }^{\circ} \mathrm{C}$.

\begin{tabular}{|c|c|c|c|c|c|c|c|}
\hline \multirow{2}{*}{ Mating pairs and lubricated conditions } & \multicolumn{7}{|c|}{ Element content (at\%) } \\
\hline & $\mathrm{C}$ & $\mathrm{O}$ & $\mathrm{Fe}$ & Mo & $\mathrm{S}$ & $\mathrm{Zn}$ & $\mathrm{P}$ \\
\hline GLC/steel, base oil & 22.58 & 53.34 & 18.91 & - & - & - & - \\
\hline GLC/steel, MoDTC & 33.10 & 4.78 & 50.50 & 9.18 & 2.26 & - & - \\
\hline GLC/steel, MoDTC+ZDDP & 32.82 & 3.96 & 59.59 & 0.97 & 1.27 & 0.99 & 0.40 \\
\hline a-C:H/steel, base oil & 18.63 & 19.65 & 59.25 & - & - & - & - \\
\hline a-C:H/steel, MoDTC & 71.25 & 1.76 & 21.89 & 2.81 & 1.97 & - & - \\
\hline a-C:H/steel, MoDTC+ZDDP & 15.54 & 6.95 & 71.22 & 0.60 & 1.29 & 2.25 & 1.01 \\
\hline ta-C/steel, base oil & 25.04 & 6.66 & 66.64 & - & - & - & - \\
\hline ta-C/steel, MoDTC & 41.10 & 5.43 & 40.71 & 7.60 & 3.99 & - & - \\
\hline ta-C/steel, MoDTC+ZDDP & 31.53 & 3.61 & 61.02 & 0.94 & 1.71 & 0.96 & 0.23 \\
\hline
\end{tabular}


located at approximately $1,580 \mathrm{~cm}^{-1}$ [31]. The D peak is attributed to the breathing modes of $\mathrm{sp}^{2}$ atoms in rings and the $G$ peak is attributed to the bond stretching of all pairs of $\mathrm{sp}^{2}$ atoms in both rings and chains [32]. Higher values of the $I_{D} / I_{G}$ ratio mean a higher $\mathrm{sp}^{2} / \mathrm{sp}^{3}$ ratio and a higher degree of graphitization.

By observing the Raman spectra of wear tracks on the coated substrate at 25 and $90{ }^{\circ} \mathrm{C}$, it was found that most of the $I_{\mathrm{D}} / I_{\mathrm{G}}$ ratios varied little, which proved that no obvious graphitization occurred. The only exception was the $I_{\mathrm{D}} / I_{\mathrm{G}}$ ratio of ta-C/ta-C under MoDTC-containing oil lubrication, which increased after wear, as shown in Fig. 10. Moreover, no other peaks appeared in the spectra, which indicated that the formation of tribofilm derived from additives on the coated substrate was difficult.

To further investigate the composition of tribochemical products and the formation of carbon transfer films, Raman spectroscopy was performed on the wear scars of the mating balls.

Figure 11 shows the Raman spectra of wear scars on mating balls of GLC. It was observed from Fig. 11(a) that no sign of an increase in the $I_{D} / I_{G}$ ratio of the GLC coating on the ball lubricated by base oil at $90{ }^{\circ} \mathrm{C}$, which was similar to the coated substrate. The characteristic peak of $\mathrm{Fe}_{2} \mathrm{O}_{3}$ was in the range of $120-310 \mathrm{~cm}^{-1}$ [15]. Two first-order active modes, $E_{2 g}^{1}$ peak at $380 \mathrm{~cm}^{-1}$ and $A_{1 g}$ peak at $410 \mathrm{~cm}^{-1}$, related to the vibration of $\mathrm{Mo}-\mathrm{S}-\mathrm{Mo}$ layer were found [33]. The peak near $820 \mathrm{~cm}^{-1}$ indicates the presence of $\mathrm{MoO}_{3}$ [34]. The characteristic peak of $\mathrm{Fe}_{3} \mathrm{O}_{4}$ was near $680 \mathrm{~cm}^{-1}$ [35]. The peak

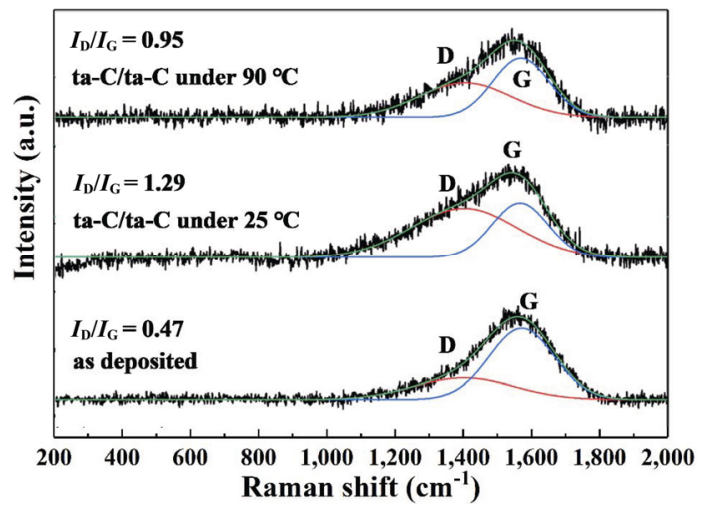

Fig. 10 Raman spectra of wear tracks on ta-C coated substrates lubricated by MoDTC. near $926 \mathrm{~cm}^{-1}$ was assigned to $\mathrm{Mo}=\mathrm{C}$ stretching in $\beta-\mathrm{FeMoO}_{4}$ [36]. For GLC/GLC, when ZDDP was added, the $\mathrm{MoS}_{2}$ peak became less intense, which indicated that ZDDP inhibited its generation. However, after the addition of ZDDP, the increased intensity of amorphous carbon peaks was observed, which indicated that the carbon content of the tribofilm increased and the iron oxide peak disappeared simultaneously, which proved that ZDDP could effectively inhibit metal oxidation, or protect the ball coating without exposing the steel substrate. For GLC/steel, a weak $\mathrm{Fe}_{3} \mathrm{O}_{4}$ peak appeared, which indicated that the ferrous surface was further oxidized under base oil lubrication. After adding MoDTC, strong $\mathrm{MoS}_{2}$ and $\mathrm{Fe}_{2} \mathrm{O}_{3}$ peaks occurred. For MoDTC+ZDDP-containing oil lubrication, apart from $\mathrm{MoS}_{2}$ and $\mathrm{Fe}_{2} \mathrm{O}_{3}$ characteristic peaks, weak peaks near 820 and $926 \mathrm{~cm}^{-1}$ also appeared, indicating that small amounts of $\mathrm{MoO}_{3}$ and $\beta-\mathrm{FeMoO}_{4}$ appeared on the wear scar.

The Raman spectra at $25{ }^{\circ} \mathrm{C}$ are shown in Fig. 11(b). For GLC/GLC, only the amorphous carbon peaks were seen under the lubrication of base oil and MoDTC-containing oil. The $\mathrm{MoS}_{2}$ peaks were exhibited weakly under the lubrication of MoDTC+ZDDPcontaining oil. For GLC/steel, the characteristic peaks were less intense, indicating that the additives were less effective under such circumstances.

Figure 12 shows the Raman spectra of wear scars on mating balls of a-C:H. At $90{ }^{\circ} \mathrm{C}$, the selfmated tribopairs did not undergo graphitization for a-C:H lubricated by base oil as shown in Fig. 12(a). It showed less intense $\mathrm{MoS}_{2}$ characteristic peaks lubricated by MoDTC+ZDDP-containing oil. After the addition of ZDDP, the weak peak near $926 \mathrm{~cm}^{-1}$ indicated the existence of $\beta-\mathrm{FeMoO}_{4}$. For a-C:H/steel, base oil lubrication generated a large amount of iron oxide. When ZDDP was added, the $\mathrm{MoS}_{2}$ peaks were enhanced, and the amount of transferred amorphous carbon seemed to increase. The weak characteristic peaks of $\mathrm{MoO}_{3}$ and $\beta$ $\mathrm{FeMoO}_{4}$ also appeared.

At $25{ }^{\circ} \mathrm{C}$, no peaks apart from those of amorphous carbon were found for a-C:H/a-C:H. The additives affected the steel-mated pairs, as observed from the $\mathrm{MoS}_{2}$ peaks in Fig. 12(b). The transferred carbon 

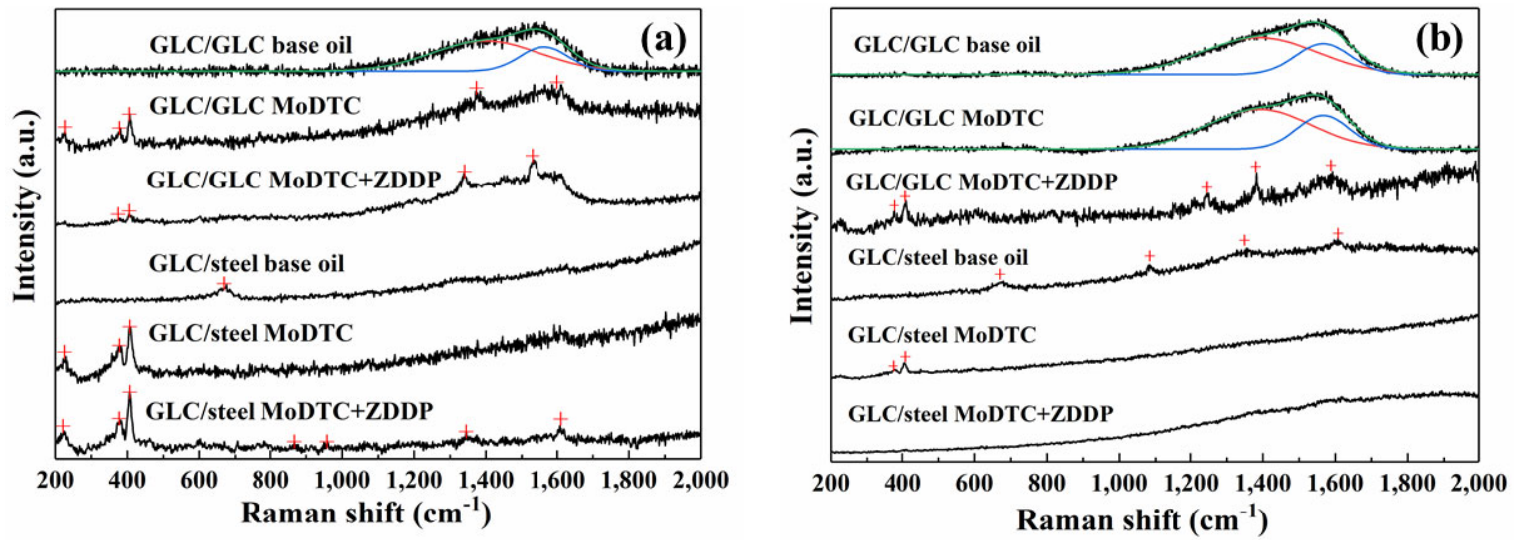

Fig. 11 Raman spectra of wear scars on mating balls of GLC at (a) $90{ }^{\circ} \mathrm{C}$ and (b) $25{ }^{\circ} \mathrm{C}$.
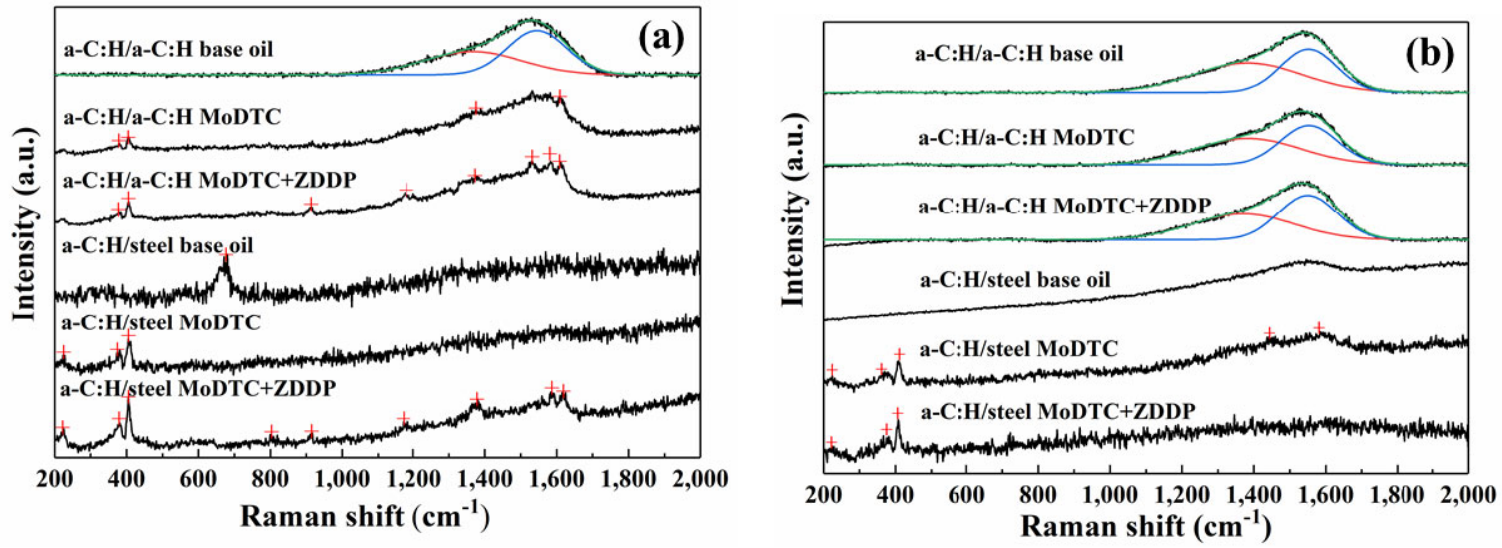

Fig. 12 Raman spectra of wear scars on mating balls of a-C:H at (a) $90{ }^{\circ} \mathrm{C}$ and (b) $25{ }^{\circ} \mathrm{C}$.

was confirmed for a-C:H/steel lubricated by MoDTC and base oil since the broad peaks appeared between 1,300 and $1,600 \mathrm{~cm}^{-1}$.

Figures 13(a) and 13(b) shows the Raman spectra of wear scars on mating balls of ta-C at 90 and $25{ }^{\circ} \mathrm{C}$, respectively. At $90{ }^{\circ} \mathrm{C}$, for ta-C/ta-C, no obvious characteristic peaks appeared under base oil lubrication, but $\mathrm{MoS}_{2}$ peaks and weak carbon peaks appeared when MoDTC was added. For ta-C/steel, insignificant carbon peaks appeared under base oil lubrication, and the characteristic peaks of $\mathrm{MoS}_{2}$ were relatively lubricated by MoDTC-containing oil. When ZDDP was added, weak $\mathrm{Fe}_{2} \mathrm{O}_{3}, \mathrm{MoS}_{2}$, and $\mathrm{MoO}_{3}$ peaks appeared, and the $\beta-\mathrm{FeMoO}_{4}$ peak was more intense. In addition, there were multiple strong carbon peaks when lubricated by MoDTC+ZDDPcontaining oil.

At $25{ }^{\circ} \mathrm{C}$, for ta-C/ta-C, amorphous carbon peaks appeared under base oil lubrication, indicating the existence of a small amount of carbon residue.
Weak peaks of $\mathrm{MoS}_{2}$ were found on peaks under the lubrication of the additives. For ta-C/steel, strong $\mathrm{Fe}_{3} \mathrm{O}_{4}$ peaks appeared under base oil lubrication, indicating that the ferrous surfaces suffered severe oxidation. $\mathrm{Fe}_{2} \mathrm{O}_{3}$ and $\mathrm{MoS}_{2}$ peaks appeared when MoDTC was added, like other steel-mated pairs. Under the lubrication of MoDTC+ZDDP-containing oil, the peaks of $\beta-\mathrm{FeMoO}_{4}, \mathrm{MoO}_{3}, \mathrm{MoS}_{2}, \mathrm{Fe}_{2} \mathrm{O}_{3}$, and amorphous carbon all appeared.

\subsection{Discussion}

At $90{ }^{\circ} \mathrm{C}$, the fluctuation of the COF was very small but was very large at room temperature $\left(25^{\circ} \mathrm{C}\right)$. This may be attributed to the viscosity of the lubricant. At room temperature, the viscosity of the lubricating oil was relatively high; thus, the fluidity was poor. Under high contact stress, dry friction tended to occur in the local area owing to oil starvation during the friction process; hence, the sudden increases of COF occurred frequently. 

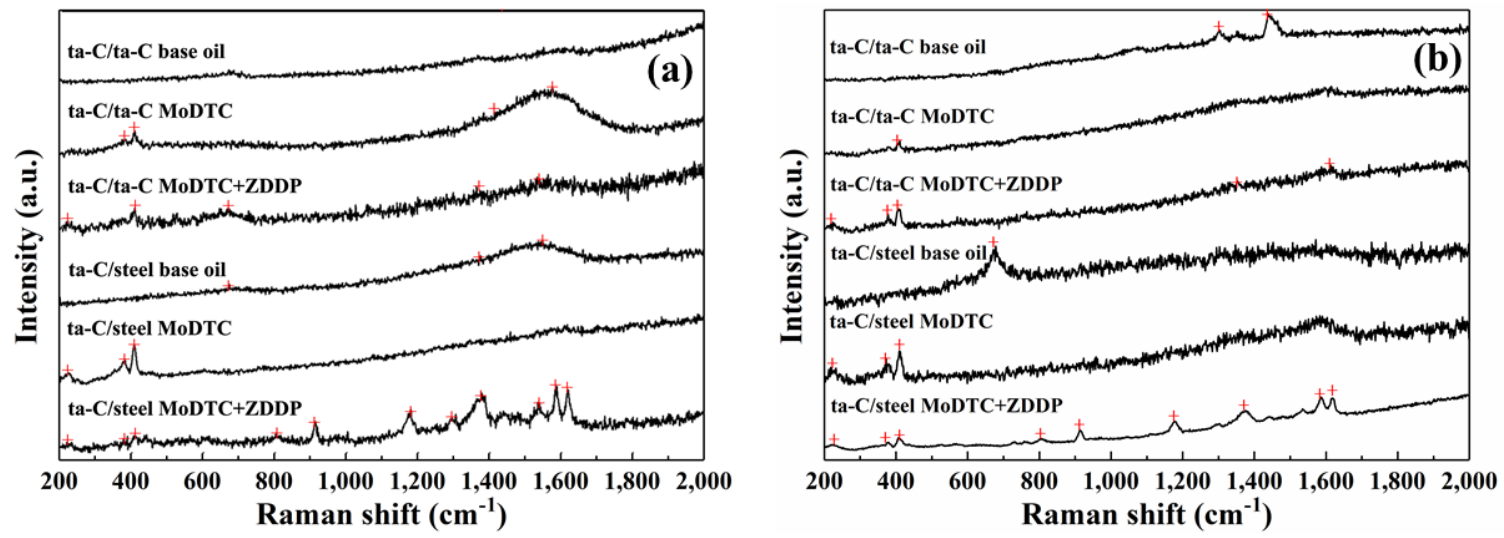

Fig. 13 Raman spectra of wear scars on mating balls of ta-C (a) $90{ }^{\circ} \mathrm{C}$ and (b) $25{ }^{\circ} \mathrm{C}$.

At the same time, as MoDTC is a kind of viscous liquid, the fluidity of lubricating oil would be further reduced after its addition, which exacerbated the COF fluctuations at room temperature. At high temperatures, the high fluidity of the base oil helped stabilize the COF. As shown in Fig. 3, the COFs of GLC/GLC and a-C:H/a-C:H at $90{ }^{\circ} \mathrm{C}$ were both stables at 0.04 , which were lower than those at $25{ }^{\circ} \mathrm{C}$. This illustrates that GLC/GLC and a-C:H/ a-C:H tribopairs have good inherent friction behaviors. However, for steel-mated tribopairs under base oil lubrication, no decrease in COF occurred at high temperatures. The reason is that the oil film thickness decreased with lubricant viscosity, leading to more surface asperities shearing against each other. The oxidation of ferrous surfaces might also increase the asperities that caused a high COF. Figures 11 and 12 show that the Raman spectra of GLC/steel and a-C:H/steel both have strong $\mathrm{Fe}_{3} \mathrm{O}_{4}$ peaks at $680 \mathrm{~cm}^{-1}$ at high temperatures, which indicated that the ferrous surface was severely oxidized under base oil lubrication. On the other hand, high temperatures promoted the decomposition of MoDTC to generate more $\mathrm{MoS}_{2}$, which helped reduce the COF. ZDDP was more reactive at high temperatures, but the tribofilm that formed on DLC/GLC had little effect on the friction.

The bearing capacity of the oil film decreased at high temperature, causing damage under high stress, resulting in severe wear. Therefore, the wear rate of the coated substrate under base oil lubrication increased at $90{ }^{\circ} \mathrm{C}$. This phenomenon is reflected in Fig. 7. The wear of ta-C/steel under base oil lubrication at $90{ }^{\circ} \mathrm{C}$ was particularly intensified, which was attributed to its high roughness and hardness. The hard asperities on the surface increased the contact stress, which damaged the oil film more severely at $90{ }^{\circ} \mathrm{C}$, resulting in more severe wear. For lubricant additives, high temperature promoted the formation of tribofilms originating from ZDDP, which effectively reduced the wear for steel-mated pairs caused by MoDTC. The increased amount of $\mathrm{MoS}_{2}$ at high temperatures also reduced the contact pressure to lower the wear rate.

Figures 8, 11(a), and 12(a) show that under the lubrication of MoDTC-containing oil, the surfaces of the wear scars on the mating balls of GLC/GLC and a-C:H/a-C:H were rich in Mo and S elements. $\mathrm{MoS}_{2}$ was confirmed on the wear scars by Raman spectra; this increased the COF, which suggested that the friction-reducing property of $\mathrm{MoS}_{2}$ was less effective than self-mated coatings. From the observation of Figs. 8 and 9, under the lubrication of MoDTC+ZDDP-containing oil, no enrichment of $P$ and $Z n$ occurred on the wear scars of the selfmated pair, except for ta-C/ta-C. In addition, the surface of ta-C was bare steel substrate. However, Mo, S, Zn, and P were present on the wear scars of the steel-mated pairs. Those above revealed that the ferrous surface is essential for ZDDP to form a tribofilm with wear resistance. By comparing Figures 4 and 5 , it can be concluded that the wear resistance of ZDDP under high temperatures was very effective for steel-mated tribopairs. Figures 11-13 show that under the lubrication of MoDTC+ZDDPcontaining oil, the peaks at 380 and $410 \mathrm{~cm}^{-1}$ of steel-mated tribopairs were stronger at $90{ }^{\circ} \mathrm{C}$, which indicated the promotion of $\mathrm{MoS}_{2}$ formation. 
It is worth noting that the peaks near 926 and $820 \mathrm{~cm}^{-1}$ corresponding to $\beta-\mathrm{FeMoO}_{4}$ and $\mathrm{MoO}_{3}$, only appeared after the addition of ZDDP. $\mathrm{MoO}_{3}$ was a common decomposition product of MoDTC, and $\beta-\mathrm{FeMoO}_{4}$ was probably generated by the reaction between ferrous surfaces and $\operatorname{MoS}_{x}(x>2)$, an intermediate decomposition product of MoDTC at low temperature [18]. In this experiment, $\mathrm{MoO}_{3}$ and $\beta-\mathrm{FeMoO}_{4}$ may act like abrasive particles. When ZDDP was added to the oil, the anti-wear tribofilm prevented the particles from directly contacting with the surface of the mating pairs. Meanwhile, $\mathrm{MoO}_{3}$ and $\beta-\mathrm{FeMoO} 4$ were embedded in the tribofilm.

In this experiment, the only graphitization occurred at ta-C/ta-C, as shown in Fig. 10. In Refs. [37, 38], it was found that increased load, the use of MoDTC additives, and metal-doping increased the $I_{\mathrm{D}} / I_{\mathrm{G}}$ ratio of the DLC coating during the friction process. However, both the Mo compound and doped metal particles could lead to increased contact stress, thus inducing graphitization. According to Haque's study [39], the temperature during friction is negatively related to the stress that induced graphitization. Although a large load of $50 \mathrm{~N}$ was used in this study, the Hertz contact stress generated by most of the tribopairs did not reach the inducing value. The ta-C/ta-C had hard asperities on both contact surfaces, which would greatly increase the contact stress to reach inducing values at 25 and $90{ }^{\circ} \mathrm{C}$, and then caused graphitization. Moreover, the spalling of ta- $\mathrm{C}$ surface occurred owing to the high contact stress of ta-C/ta-C, and the hard ta-C particles caused severe third-body abrasive wear.

\section{Conclusions}

In this study, the effects of tribopairs and temperature on the tribological behaviors of GLC and DLC coatings, lubricated by the base oil and additivecontaining oils under high Hertz contact stress, were investigated. The conclusions are as follows:

1) At high temperatures, the COF was stable owing to the low viscosity of the base oil. The wear resistance of ZDDP was also enhanced for steel-mated tribopairs. The decomposition of MoDTC was promoted to form $\mathrm{MoS}_{2}, \mathrm{MoO}_{3}$, and $\beta-\mathrm{FeMoO} 4$ under the lubrication of MoDTC+ZDDP-containing oil. However, the lower viscosity of the base oil decreased the bearing capacity of the oil film and exacerbated wear.

2) The wear condition of ta-C/ta-C was severe, which was caused by third-body abrasive wear due to its high roughness and high hardness. The only graphitization in the experiment occurred on the wear scar of ta-C/ta-C lubricated by MoDTCcontaining oil. The inherent COFs of GLC/GLC and a-C:H/a-C:H were lower than that of $\mathrm{MoS}_{2}$. The type of wear caused by MoDTC on the steelmated tribopairs was abrasive wear. This only caused wear on coatings with a hardness within a certain range and had no effect on ta-C coating with high hardness.

\section{Acknowledgements}

This work was supported by the Beijing Municipal Natural Science Foundation (3182032), the National Natural Science Foundation of China (41772389), the Pre-Research Program in National 13th Five-Year Plan (61409230603), and Joint Fund of Ministry of Education for Pre-research of Equipment for Young Personnel Project (6141A02033120).

Open Access This article is licensed under a Creative Commons Attribution 4.0 International License, which permits use, sharing, adaptation, distribution and reproduction in any medium or format, as long as you give appropriate credit to the original author(s) and the source, provide a link to the Creative Commons licence, and indicate if changes were made.

The images or other third party material in this article are included in the article's Creative Commons licence, unless indicated otherwise in a credit line to the material. If material is not included in the article's Creative Commons licence and your intended use is not permitted by statutory regulation or exceeds the permitted use, you will need to obtain permission directly from the copyright holder.

To view a copy of this licence, visit http://creativecommons.org/licenses/by/4.0/. 


\section{References}

[1] Bielaczyc P, Woodburn J, Szczotka A. An assessment of regulated emissions and $\mathrm{CO}_{2}$ emissions from a European light-duty CNG-fueled vehicle in the context of Euro 6 emissions regulations. Appl Energy 117: 134-141 (2014)

[2] Holmberg K, Andersson P, Erdemir A. Global energy consumption due to friction in passenger cars. Tribol Int 47: 221-234 (2012)

[3] Donnet C, Erdemir A. Tribology of Diamond-Like Carbon Films. New York: Springer, 2008.

[4] Meng Y G, Xu J, Jin Z M, Prakash B, Hu Y Z. A review of recent advances in tribology. Friction 8(2): 221-300 (2020)

[5] Rossi F, André B, van Veen A, Mijnarends P E, Schut H, Delplancke M P, Gissler W, Haupt J, Lucazeau G, Abello L. Effect of ion beam assistance on the microstructure of nonhydrogenated amorphous carbon. J Appl Phys 75(6): 3121-3129 (1994)

[6] Wang Y X, Wang L P, Wang S C, Zhang G A, Wood R J K, Xue Q J. Nanocomposite microstructure and environment self-adapted tribological properties of highly hard graphite-like film. Tribol Lette 40(3): 301-310 (2010)

[7] Stallard J, Mercs D, Jarratt M, Teer D G, Shipway P H. A study of the tribological behaviour of three carbonbased coatings, tested in air, water and oil environments at high loads. Surf Coat Technol 177-178: 545-551 (2004)

[8] Li Z C, Guan X Y, Wang Y X, Li J L, Cheng X Y, Lu X, Wang L P, Xue Q J. Comparative study on the load carrying capacities of DLC, GLC and CrN coatings under sliding-friction condition in different environments. Surf Coat Technol 321: 350-357 (2017)

[9] Gongyang Y J, Ouyang W E, Qu C Y, Urbakh M, Quan B G, Ma M, Zheng Q S. Temperature and velocity dependent friction of a microscale graphite-DLC heterostructure. Friction 8(2): 462-470 (2020)

[10] Liu L C, Zhou M, Jin L, Li L C, Mo Y T, Su G S, Li X, Zhu $\mathrm{H} \mathrm{W}$, Tian Y. Recent advances in friction and lubrication of graphene and other 2D materials: Mechanisms and applications. Friction 7(3): 199-216 (2019)

[11] Grossiord C, Martin J M, Varlot K, Vacher B, Le Mogne $\mathrm{T}$, Yamada Y. Tribochemical interactions between ZnDTP, MoDTC and calcium borate. Tribol Lett 8(4): 203-212 (2000)

[12] Spikes H. The history and mechanisms of ZDDP. Tribol Lett 17(2): 469-489 (2004)

[13] Yue W, Liu C Y, Fu Z Q, Wang C B, Huang H P, Liu J J. Synergistic effects between sulfurized W-DLC coating and MoDTC lubricating additive for improvement of tribological performance. Tribol Int 62: 117-123 (2013)

[14] Espejo C, Thiébaut B, Jarnias F, Wang C, Neville A, Morina A. MoDTC tribochemistry in steel/steel and steel/ diamond-like-carbon systems lubricated with model lubricants and fully formulated engine oils. J Tribol 141(1): 012301 (2019)

[15] Al-Jeboori Y, Kosarieh S, Morina A, Neville A. Investigation of pure sliding and sliding/rolling contacts in a DLC/Cast iron system when lubricated in oils containing MoDTC-Type friction modifier. Tribol Int 122: 23-37 (2018)

[16] Yue W, Liu C Y, Fu Z Q, Wang C B, Huang H P, Liu J J. Effects of molybdenum dithiocarbamate and zinc dialkyl dithiophosphate additives on tribological behaviors of hydrogenated diamond-like carbon coatings. Mater Des 64: 601-607 (2014)

[17] Kosarieh S, Morina A, Flemming J, Lainé E, Neville A. Wear mechanisms of hydrogenated DLC in oils containing MoDTC. Tribol Lett 64: 4 (2016)

[18] Okubo H, Tadokoro C, Sumi T, Tanaka N, Sasaki S. Wear acceleration mechanism of diamond-like carbon (DLC) films lubricated with MoDTC solution: Roles of tribofilm formation and structural transformation in wear acceleration of DLC films lubricated with MoDTC solution. Tribol Int 133: 271-287 (2019)

[19] de Feo M, de Barros Bouchet M I, Minfray C, Esnouf C, Le Mogne T, Meunier F, Yang L, Thiebaut B, Pavan S, Martin J M. Formation of interfacial molybdenum carbide for DLC lubricated by MoDTC: Origin of wear mechanism. Wear 370-371: 17-28 (2017)

[20] Yoshida Y, Kunitsugu S. Friction wear characteristics of diamond-like carbon coatings in oils containing molybdenum dialkyldithiocarbamate additive. Wear 414-415: 118 125 (2018)

[21] Khaemba D N, Neville A, Morina A. New insights on the decomposition mechanism of Molybdenum DialkyldiThioCarbamate (MoDTC): A Raman spectroscopic study. RSC Adv 6(45): 38637-38646 (2016)

[22] de Barros'Bouchet M I, Martin J M, Le-Mogne T, Vacher B. Boundary lubrication mechanisms of carbon coatings by MoDTC and ZDDP additives. Tribol Int 38(3): 257-264 (2005)

[23] Tasdemir H A, Tokoroyama T, Kousaka H, Umehara N, Mabuchi Y. Friction and wear performance of boundarylubricated DLC/DLC contacts in synthetic base oil. Procedia Eng 68: 518-524 (2013)

[24] Ren S M, Zheng S X, Pu J B, Lu Z B, Zhang G A. Study of tribological mechanisms of carbon-based coatings in antiwear additive containing lubricants under high temperature. RSC Adv 5(81): 66426-66437 (2015)

[25] Austin L, Liskiewicz T, Kolev I, Zhao H Y, Neville A. The influence of anti-wear additive ZDDP on doped and undoped diamond-like carbon coatings. Surf Interface Anal 47(7): 755-763 (2015)

[26] Vengudusamy B, Green J H, Lamb G D, Spikes H A. Behaviour of MoDTC in DLC/DLC and DLC/steel contacts. Tribol Int 54: 68-76 (2012)

[27] Dorgham A, Parsaeian P, Neville A, Ignatyev K, 
Mosselmans F, Masuko M, Morina A. In situ synchrotron XAS study of the decomposition kinetics of ZDDP triboreactive interfaces. $R S C A d v$ 8(59): 34168-34181 (2018)

[28] Hamrock B J, Dowson D. Isothermal elastohydrodynamic lubrication of point contacts: Part III-fully flooded results. J Lubricat Technol 99(2): 264-275 (1977)

[29] Dowson D, Jin Z M. Metal-on-metal hip joint tribology. Proc Inst Mech Eng $H \mathrm{~J}$ Eng Med 220(2): 107-118 (2006)

[30] Sugimoto I, Honda F, Inoue K. Analysis of wear behavior and graphitization of hydrogenated DLC under boundary lubricant with MoDTC. Wear 305(1-2): 124128 (2013)

[31] Casiraghi C, Ferrari A C, Robertson J. Raman spectroscopy of hydrogenated amorphous carbons. Phys Rev B 72(8): 085401 (2005)

[32] Ferrari A C. Determination of bonding in diamond-like carbon by Raman spectroscopy. Diam Relat Mater 11(3-6): 1053-1061 (2002)

[33] Wang P, Yue W, Lu Z B, Zhang G A, Zhu L N. Friction and wear properties of $\mathrm{MoS}_{2}$-based coatings sliding against $\mathrm{Cu}$ and $\mathrm{Al}$ under electric current. Tribol Int 127:

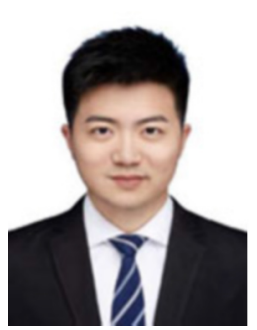

Kang LIU. He got his master degree in 2020 at China University of Geosciences (Beijing). His research

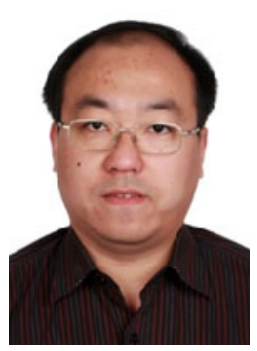

Jia-jie KANG. He got his Ph.D. degree in 2013 at China University of Geosciences (Beijing). He is an associate professor at the China

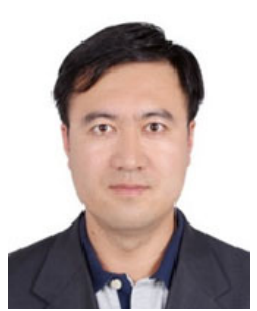

Guang-an ZHANG. He received his Ph.D. degree from Lanzhou University in 2008. After then, he has been working in the State Key Laboratory of Solid Lubrication,
379-388 (2018)

[34] Kim H M, Fukumoto T, Hayashi S, Yamamoto K. Raman study of crystal structure of gas-evaporated $\mathrm{MoO}_{3}$ microcrystals. J Phys Soc Jpn 63(6): 2194-2201 (1994)

[35] Shebanova O N, Lazor P. Raman study of magnetite $\left(\mathrm{Fe}_{3} \mathrm{O}_{4}\right)$ : Laser-induced thermal effects and oxidation. $J$ Raman Spectrosc 34(11): 845-852 (2003)

[36] Wang Y H, He P, Lei W, Dong F Q, Zhang T H. Novel $\mathrm{FeMoO}_{4} /$ graphene composites based electrode materials for supercapacitors. Compos Sci Technol 103: 16-21 (2014)

[37] Yue W, Liu C Y, Fu Z Q, Wang C B, Huang H P, Liu J J. Effects of tungsten doping contents on tribological behaviors of tungsten-doped diamond-like carbon coatings lubricated by MoDTC. Tribol Lett 58(2): 31 (2015)

[38] Yang L Q, Neville A, Brown A, Ransom P, Morina A. Friction reduction mechanisms in boundary lubricated W-doped DLC coatings. Tribol Int 70: 26-33 (2014)

[39] Haque T, Morina A, Neville A, Kapadia R, Arrowsmith S. Effect of oil additives on the durability of hydrogenated DLC coating under boundary lubrication conditions. Wear 266(1-2): 147-157 (2009)

interests include lubricating additives and carbonbased films.
University of Geosciences (Beijing). He has authored or co-authored more than 100 journal papers. His research interests are lubricating additives and thermal spray coatings.
Lanzhou Institute of Chemical Physics, Chinese Academy of Sciences. His research interest focuses on the tribological mechanism and application of carbon-based thin films. 


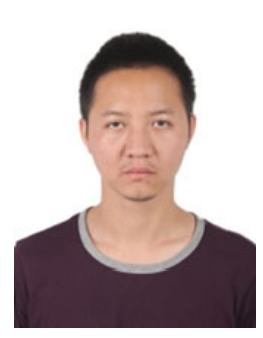

Zhi-bin LU. He received his Ph.D. degree from Lanzhou University in 2009. After then, he has been working in the State Key Laboratory of Solid Lubrication, Lanzhou

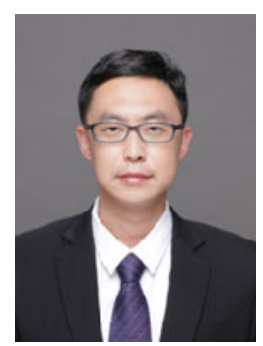

Wen YUE. He got his Ph.D. degree in 2009 at China University of Geosciences (Beijing). He is a professor at China University of
Institute of Chemical Physics, Chinese Academy of Sciences. In recent years, he has been studying on the tribological mechanism of carbon-based thin films and the new theory of super-low friction.
Geosciences (Beijing). He has authored or coauthored more than 150 journal papers. His research interests are lubricating additives and carbon-based thin films. 